\title{
Are Drug-Eluting Stents Safe and Effective in the Long Term?
}

\author{
Sanjay Sastry and Marie-Claude Morice \\ Institut Cardiovasculaire Paris Sud, Massy - France
}

\begin{abstract}
The introduction of drug-eluting stents in 2002 revolutionized interventional cardiology by minimizing restenosis. Reports of increased late stent thrombosis with these stents compared with bare metal stents, probably due to delayed endothelialization, emerged late in 2006. These studies contained serious methodological flaws, however. Subsequent meta-analyses clearly showed only a small incremental risk of late stent thrombosis across all patient groups. Importantly, a significant and sustained benefit of drug-eluting stents due to reduced restenosis and thus repeat revascularization was also shown. Several 'real-world' registries have confirmed these results and suggested that the use of these stents in more complex situations is not associated with adverse outcomes. Stent thrombosis is a multifactorial problem, in which the stent is only one element. Further research is required to determine optimal procedural technique and antiplatelet regimens. Drug-eluting stents are safe and effective in the long-term, though intensive research continues into ways to reduce the risk of stent thrombosis in the next generation.
\end{abstract}

\section{Introduction}

Drug-eluting stents (DES) arrived in the world of percutaneous coronary intervention (PCI) in 2002, and almost immediately began to change modern cardiology. The use of standard bare-metal stents (BMS) had vastly reduced the incidence of emergency coronary bypass grafting (CABG) and acute vessel thrombosis during the 1990's (Figure 1) ${ }^{1,2}$.

DES were shown in randomized trials to deal with the remaining drawback of stents, the occurrence of restenosis. The six-month follow-up of the RAVEL study confirmed a $0 \%$ rate of restenosis, target vessel revascularization (TVR) and stent thrombosis ${ }^{3}$. The SIRIUS study showed that sirolimuseluting stents (SES) were associated with a highly significant

\section{Keywords}

Drug - eluting stents; restenosis, thrombosis; percutaneous intervention thrombosis.

\footnotetext{
Mailing address: Marie-Claude Morice •

Institut Cardiovasculaire Paris Sud, 6 Avenue du Noyer Lambert, 91300, Massy - France

E-mail: mc.morice@icps.com.fr

Manuscript received May 20, 2008; revised manuscript received June 17, 2008; accepted July 10, 2008.
}

reduction in in-segment restenosis compared with BMS, and that this difference was evident across the range of patient and lesion characteristics ${ }^{4}$. The TAXUS IV study showed similar results with paclitaxel-eluting stents $(\mathrm{PES})^{5}$.

\section{The end of DES?}

The first clouds appeared on the horizon in early 2004, however, with a report detailing 4 patients who had suffered stent thrombosis more than 11 months after DES implantation following discontinuation of antiplatelet therapy ${ }^{6}$. Doubts were also raised following a histological study of DES months after implantation, in which delayed endothelialization was evident ${ }^{7}$. The authors linked this delay with a higher risk of stent thrombosis in DES in comparison with BMS. Subsequently the BASKET-LATE registry study, which followed patients up to 18 months post-stenting, showed an increased frequency of late stent thrombosis and cardiac death or myocardial infarction (MI) following cessation of clopidogrel in patients treated with DES in comparison with BMS (Figure 2$)^{8}$.

The real backlash against DES started at the European Society Congress in September 2006, when Camenzind presented a meta-analysis of randomized trials on firstgeneration DES showing a higher frequency of death and Q-wave $\mathrm{MI}$ in patients treated with DES in comparison with $\mathrm{BMS}^{9}$. The results were not statistically significant but did show a clear trend between 18 months and 3 years after stent implantation, both for PES and SES. In another high profile presentation, Nordmann suggested that SES were associated with a significant increase in non-cardiac mortality at 2 and 3 years of follow-up when compared with $\mathrm{BMS}^{10}$. These reports led to sensational headlines in the mass media including newspapers like The New York Times and The Wall Street Journal. However, there were two major methodological limitations to the Camenzind et $\mathrm{al}^{9}$ and Nordmann et $\mathrm{al}^{10}$ studies. Firstly, neither was a true meta-analysis, since the data used were collated from papers and presentations rather than 'patient-level' information. Secondly the definitions of stent thrombosis varied between the included studies to such an extent that coherent meta-analysis was invalid. Despite this, DES penetration in the US fell by $12 \%$ in the six months following the ESC, while in Europe the steady rise in use was halted, and penetration remained fixed at $50 \%{ }^{11,12}$.

There were two immediate positive outcomes from the inappropriate hysteria about DES thrombosis. The first was the development of accepted definitions of stent thrombosis by the Academic Research Consortium (ARC) at the behest of the FDA prior to a special meeting of their advisory panel on 


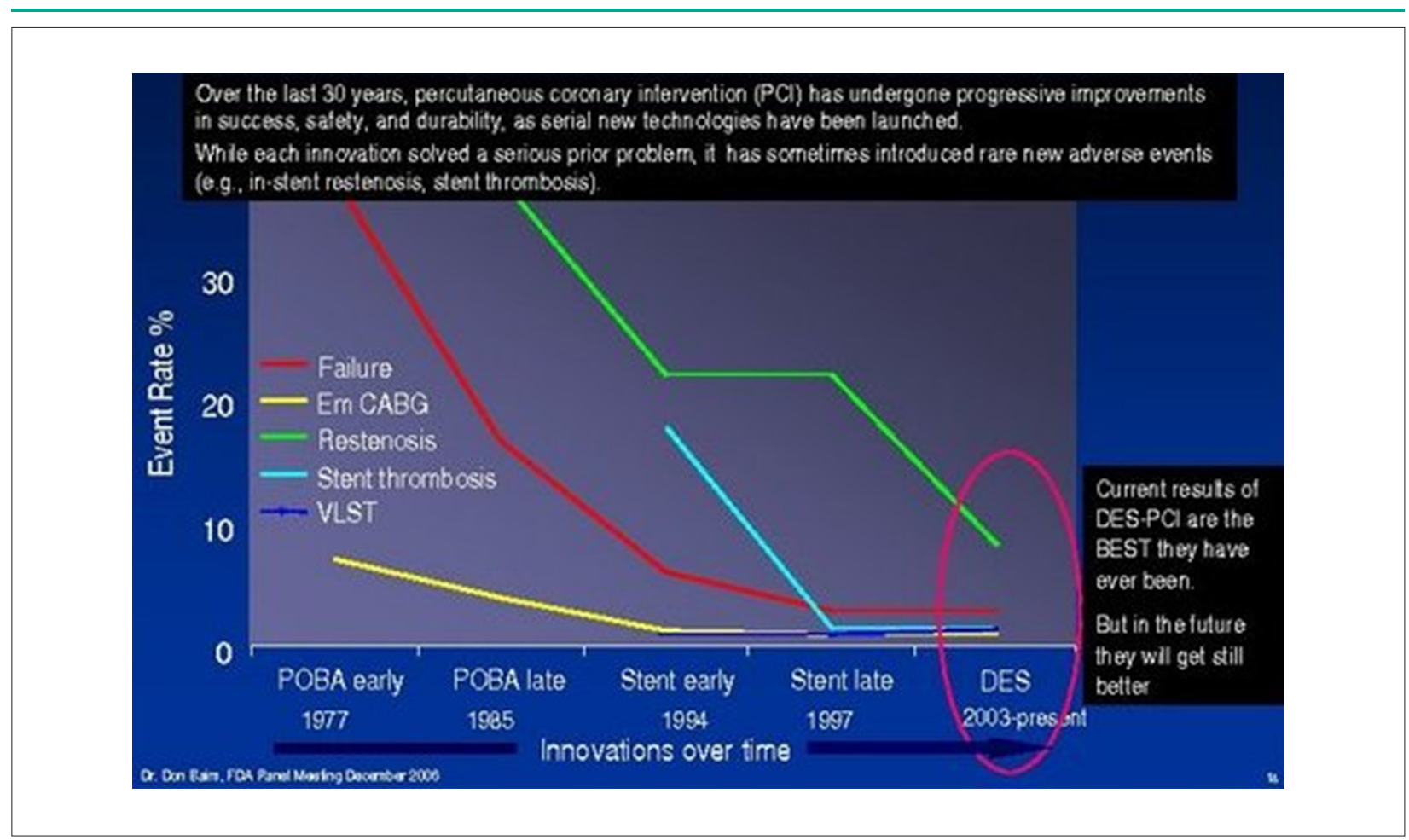

Figure 1 - Restenosis, the Achilles heel of angioplasty, and the effect of DES'.

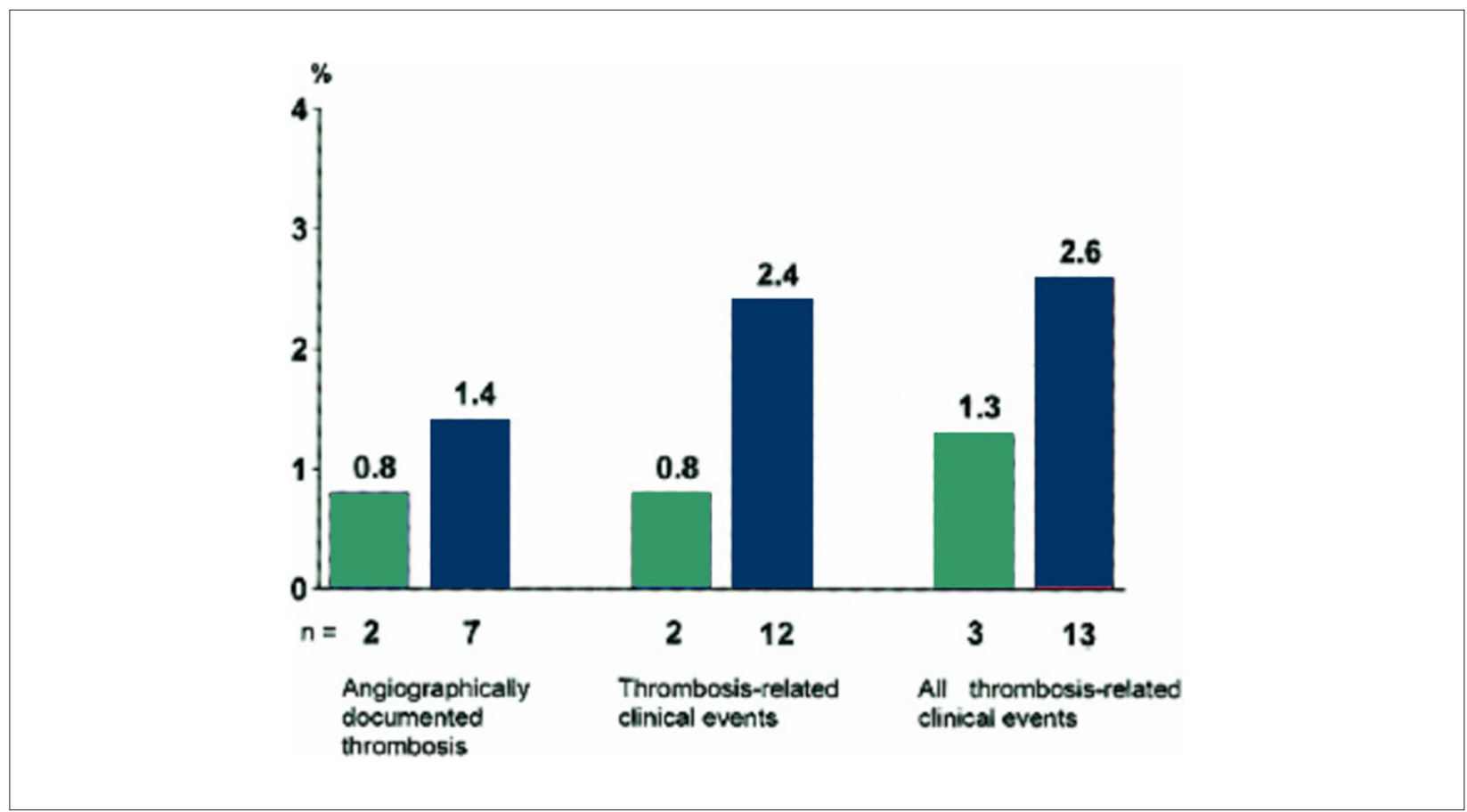

Figure 2 - Late stent thrombosis and related clinical events in the BASKET-LATE study. DES - green; BMS - blue. Low overall rates with non-significant differences.

DES safety in December $2006^{13}$. A second positive outcome was that independent meta-analyses were performed on the many studies of DES and BMS using 'patient-level' data to provide a clearer answer to this question.
The real risk of stent thrombosis with DES

An edition of the New England Journal of Medicine in February 2007 contained several such studies. A meta-analysis of the incidence of stent thrombosis in 8 major randomized 


\section{Review Article}

studies found no significant difference between patients treated with DES and BMS using the ARC definitions (definite or probable stent thrombosis in SES 1.5\% vs BMS 1.7\%, $\mathrm{p}=0.70$; and PES 1.8\% vs BMS 1.4\%, $\mathrm{p}=0.52$ ) (Figure 3$)^{14}$. Another meta-analysis of 9 randomized trials concluded that stent thrombosis after one year was more common with PES and SES than BMS, although both DES were associated with a marked reduction in target-lesion revascularization (TLR). ${ }^{15} \mathrm{At}$ 4 years there were no significant differences in the cumulative event rates of death or MI (Figure 4). Similarly a meta-analysis of 4 trials comparing SES and BMS showed no significant differences between the two treatments in terms of death, $\mathrm{MI}$ or stent thrombosis up to four years post-stent insertion ${ }^{16}$.

In the same edition, however, the Swedish Coronary Angiography and Angioplasty registry (SCAAR) found an increased rate of death in patients treated with DES in comparison with BMS at 3 years (adjusted relative risk (RR) $1.18,95 \%$ confidence interval $(\mathrm{Cl}) 1.05$ to 1.37$)^{17}$. Interestingly after an additional year of follow-up, providing a total of 13,786 DES and 21,480 BMS patients, there was no significant difference in mortality between the two groups (RR 1.03, 95\% $\mathrm{Cl} 0.94$ to 1.14$)^{18}$. Other large scale 'real-world' registries have similarly reported comparable or lower mortality between the two groups ${ }^{19-22}$. These 'real world' registries have also suggested that use of DES in more complex situations is not associated with adverse outcomes.
Perhaps the most important study following the DES 'crisis' has been the network meta-analysis that included all relevant studies of first-generation DES ${ }^{23}$. The authors included 38 trials with a total of 18,023 patients and a follow-up of up to 4 years. Mortality was similar between SES, PES and BMS (Figure 5). There were no significant differences in the risk of definite stent thrombosis ( 0 days to 4 years). On the basis of a more marked reduction in TLR in SES than PES-treated patients, and a lower frequency of $\mathrm{MI}$ in the SES-treated patients, the authors concluded that SES appeared clinically better.

The concerns raised in previous studies about the risk of stent thrombosis in diabetic patients were also addressed in a recent meta-analysis of diabetic and non-diabetic patients in 5 randomized trials comparing PES and $\mathrm{BMS}^{24}$. At 4-year follow-up the authors found no significant differences between PES and BMS regarding death (8.4\% vs $10.3 \%, \mathrm{p}=0.61), \mathrm{MI}$ (6.9\% vs $8.9 \%, p=0.17)$ or stent thrombosis $(1.4 \%$ vs $1.2 \%$, $\mathrm{p}=0.92)$. They did find a significant reduction in TLR in the PES-treated patients (12.5\% vs 24.7\%, $p<0.0001$ ).

As a result of all these studies, the safety of DES has been proven. A higher risk of late stent thrombosis may be the result of a drug coating that reduces longer-term ischemia due to restenosis. Indeed the risk of stent thrombosis following DES in a small proportion of patients has been shown to be offset by the benefit in reducing TLR in much higher proportion of

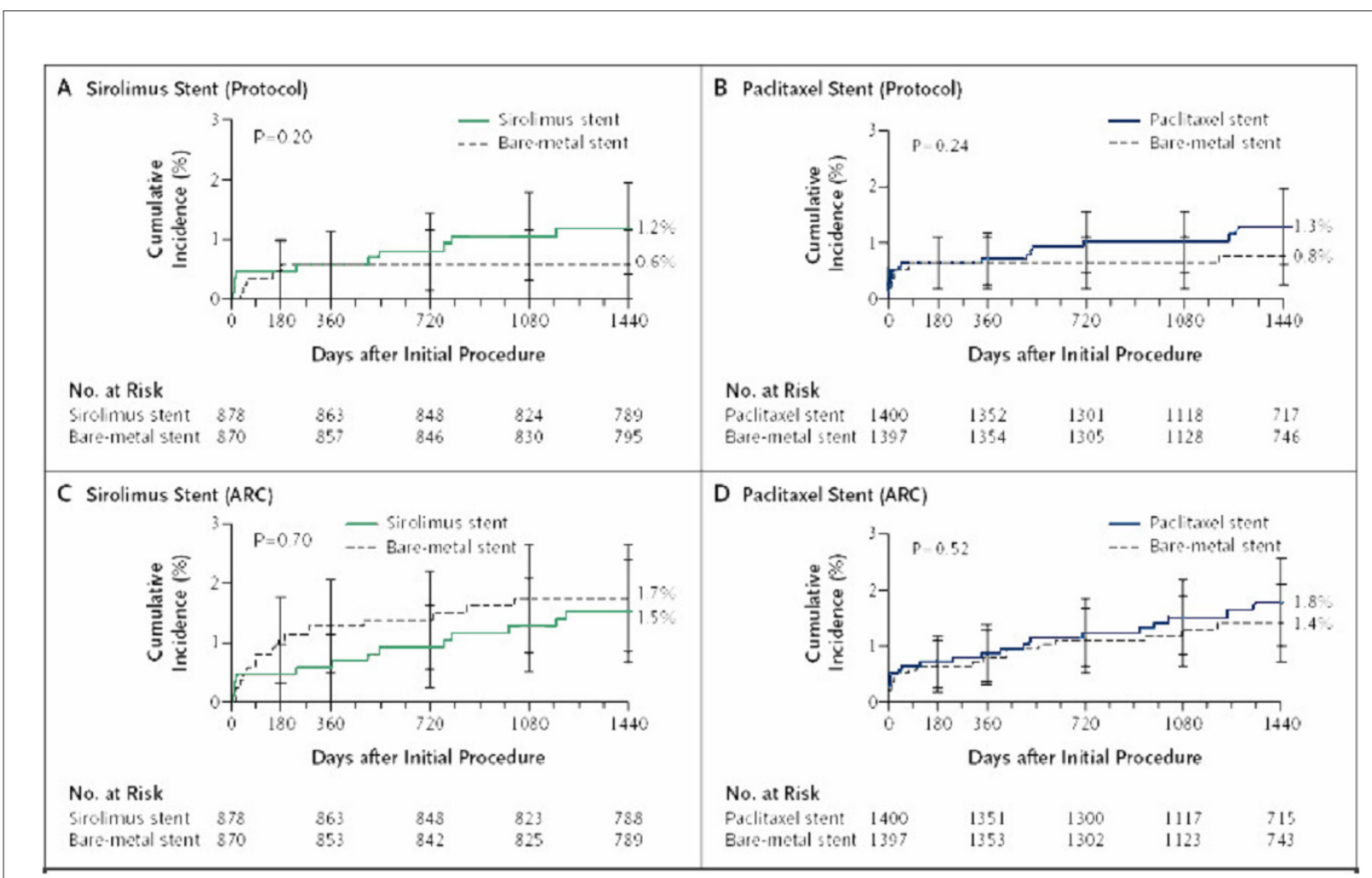

Figure 3 - Cumulative incidence of stent thrombosis at 4 years post-implantation according to study protocol definitions versus Academic Research Consortium (ARC) definitions ${ }^{14}$. A and B show comparisons of stent thrombosis in patients with sirolimus-eluting stents and paclitaxel-eluting stents, as compared with bare metal stents according to the definition of stent thrombosis used in the original study protocol. C and D show data from the same trials with the definition of definite or probable stent thrombosis recommended by the ARC. 


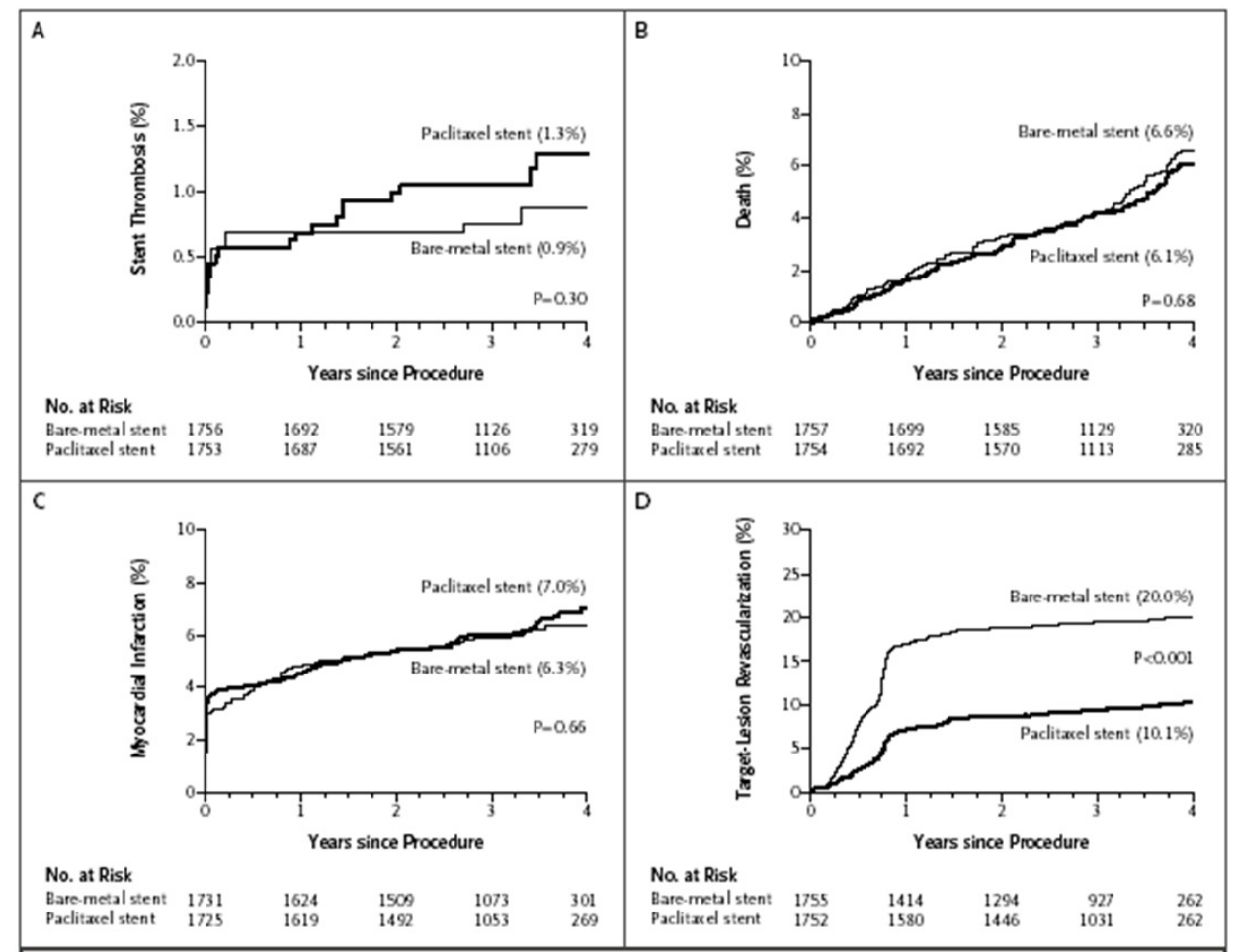

Figure 4 - Kaplan-Meier curves representing the estimated 4-year cumulative incidence rates of stent thrombosis (A), death (B), myocardial infarction (C) and target lesion revascularization $(D)$ for the pooled randomized trials of paclitaxel-eluting stents and bare metal stents ${ }^{15}$. Median duration of follow-up 3.2 years.

cases treated, despite the more frequent occurrence of death or MI following stent thrombosis ${ }^{25}$.

\section{The spotlight on stent thrombosis, its causes and how to reduce it}

The greatest benefit of the DES controversy has, however, been the resulting spotlight on stent thrombosis and how to prevent it. The multifactorial nature of stent thrombosis has long been recognized (Figure 6) ${ }^{26}$. Indeed late stent thrombosis is not a problem limited to DES ${ }^{27}$. Recognized risk factors for stent thrombosis in DES include renal failure, insulindependent diabetes mellitus, calcified lesions, impaired ventricular function, stent underexpansion and residual reference segment stenosis ${ }^{28,29}$.

Recently interest has been growing in the field of responsiveness to antiplatelet treatment with clopidogrel and aspirin. High post-treatment platelet reactivity is one of the best ways to assess clopidogrel nonresponsiveness and has been shown to be an independent risk factor for stent thrombosis in patients receiving DES on multivariate analysis ${ }^{30}$. Individual responsiveness to clopidogrel may be influenced by genetic and cellular factors as well as clinical factors such as patient compliance or clopidogrel dose (Figure $7)^{31}$. Patients with diabetes mellitus may be particularly susceptible to problems of nonresponsiveness to antiplatelet treatment. In a study of 54 diabetic patients who had been taking long-term dual antiplatelet therapy, withdrawal of clopidogrel was associated with both proinflammatory and prothrombotic effects ${ }^{32}$. In another study comparing aspirin responsiveness at different dosages in diabetics and nondiabetics, patients with diabetes had a higher prevalence of aspirin resistance at a dose of $81 \mathrm{mg}$ per day (27\% vs $4 \%$; $p=0.001)^{33}$. Higher doses of aspirin significantly decreased aspirin resistance in diabetics. In a study of 135 patients with coronary artery disease on long-term dual antiplatelet therapy, aspirin resistance was found in $44 \%$ of patients, and was more frequent in diabetics than non-diabetics (Figure $8)^{34}$. Optimal management of patients with clopidogrel and/or aspirin resistance remains unclear. Indefinite dual antiplatelet therapy is clearly unfeasible. Testing for resistance to aspirin before cessation of clopidogrel may provide important information, and gradual discontinuation of clopidogrel therapy also warrants further investigation.

\section{Future developments in DES}

The spotlight on the deficiencies of first-generation DES has also accelerated the development of the next generation. An antibody-coated stent which aims to enhance vessel healing after $\mathrm{PCl}$ is already available and the recommended duration of dual antiplatelet therapy is only one month ${ }^{35}$. Bioabsorbable stents are also of considerable interest in terms of reducing the risk of stent thrombosis. A recent study of 30 patients 

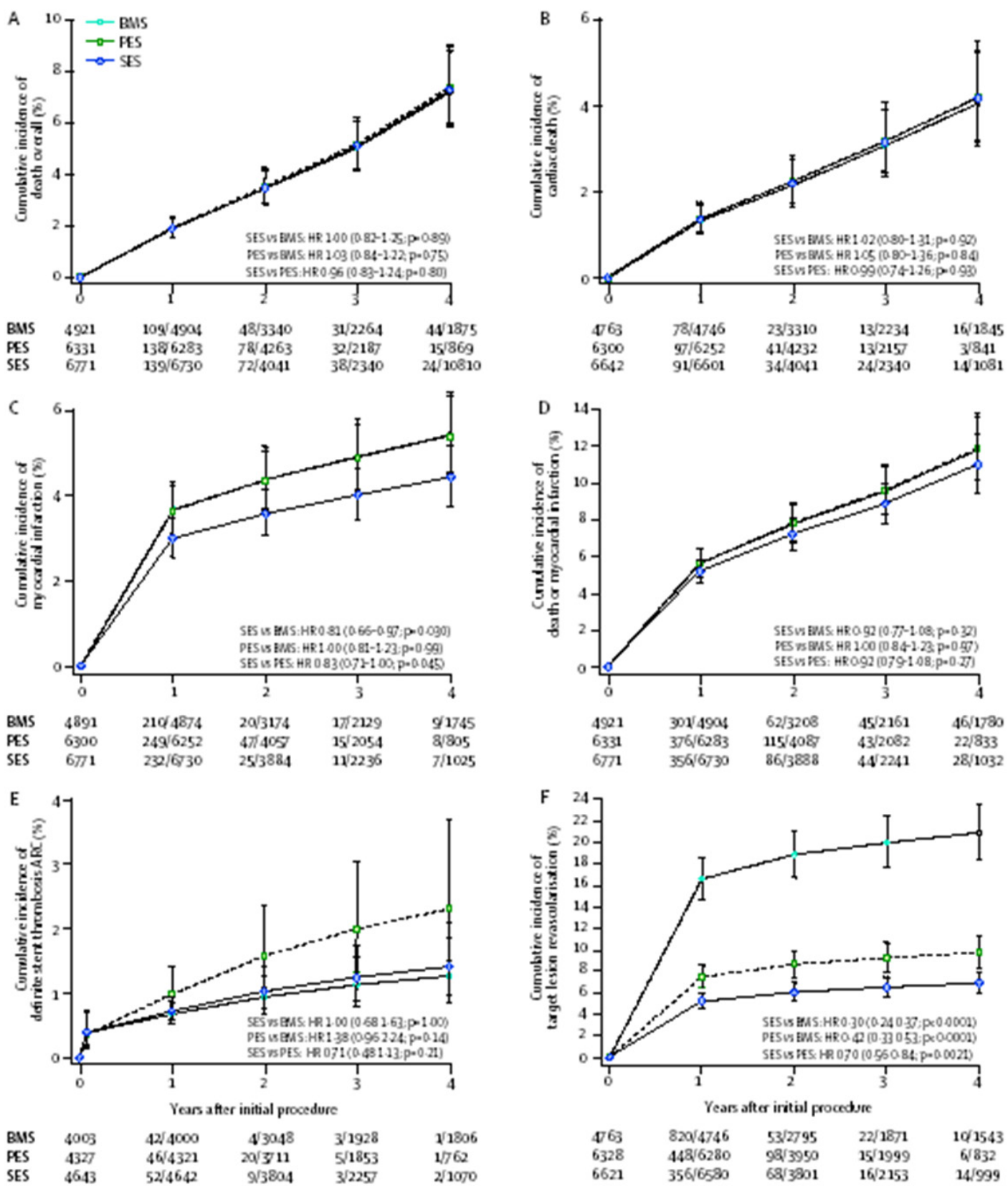

Figure 5 - Cumulative incidences estimated from the network meta-analysis for the three stent types ${ }^{23}$. (A) Overall mortality, (B) Cardiac death, (C) myocardial infarction (D) composite of death or myocardial infarction, (E) definite stent thrombosis according to ARC definitions, and (F) target lesion revascularization. BMS - bare metal stent, PES - paclitaxel-eluting stent, SES - sirolimus-eluting stent.

who received a bioabsorbable everolimus-eluting stent showed encouraging results with no late stent thrombosis and a $3.3 \%$ major adverse cardiac event rate at 1 year $^{36}$. Other stents under development that may reduce stent thrombosis include polymerless DES, and a new generation of DES with a biodegradable polymer is coming on the market.

\section{Conclusions}

First-generation DES are associated with a slightly increased risk of late stent thombosis when compared with BMS; this is largely due to delayed endothelialization and is not translated into an increased risk of death or MI up to four years of follow-up. This slightly increased risk is compensated 


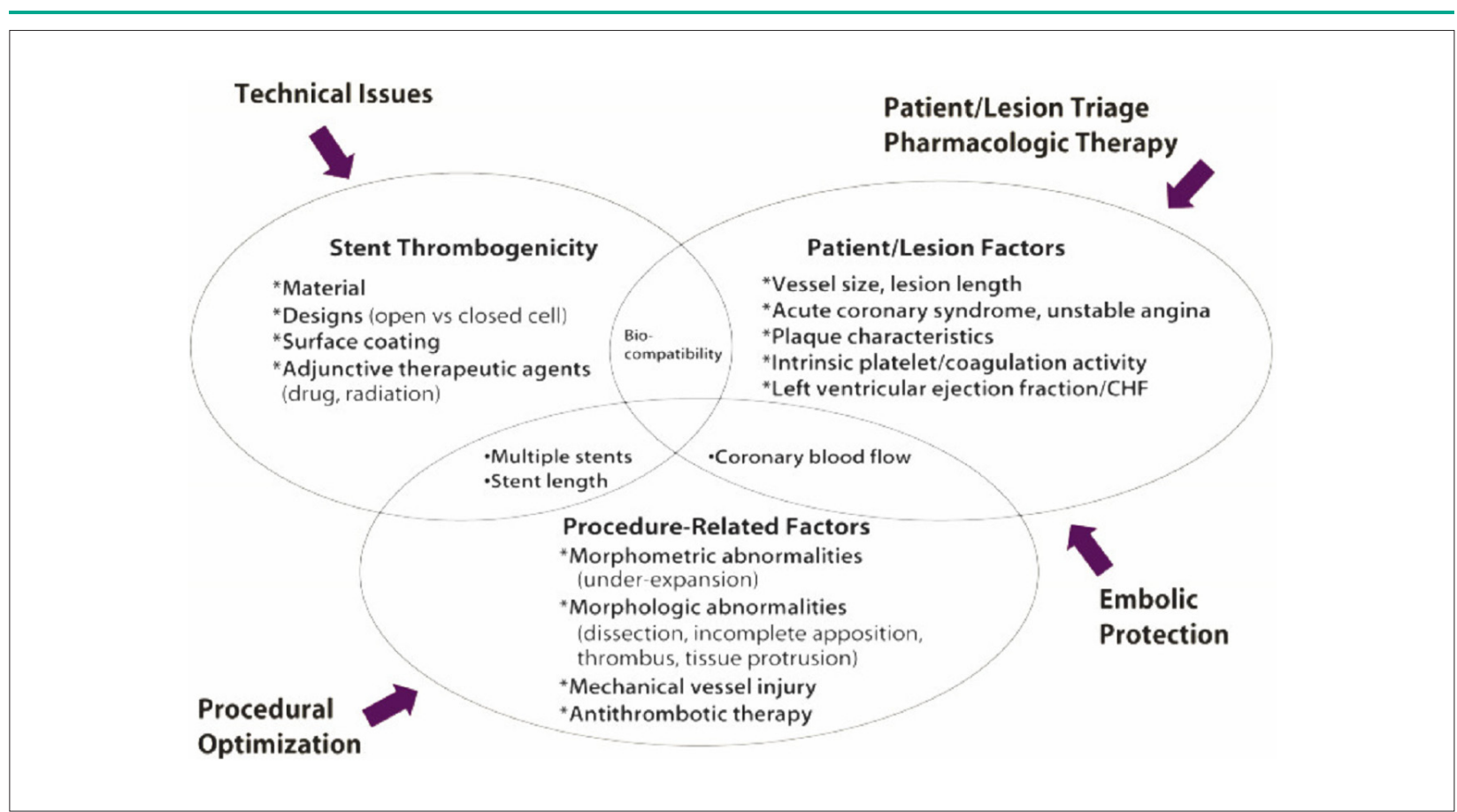

Figure 6 - Multiple and diverse factors contributing to stent thrombosis ${ }^{26}$.

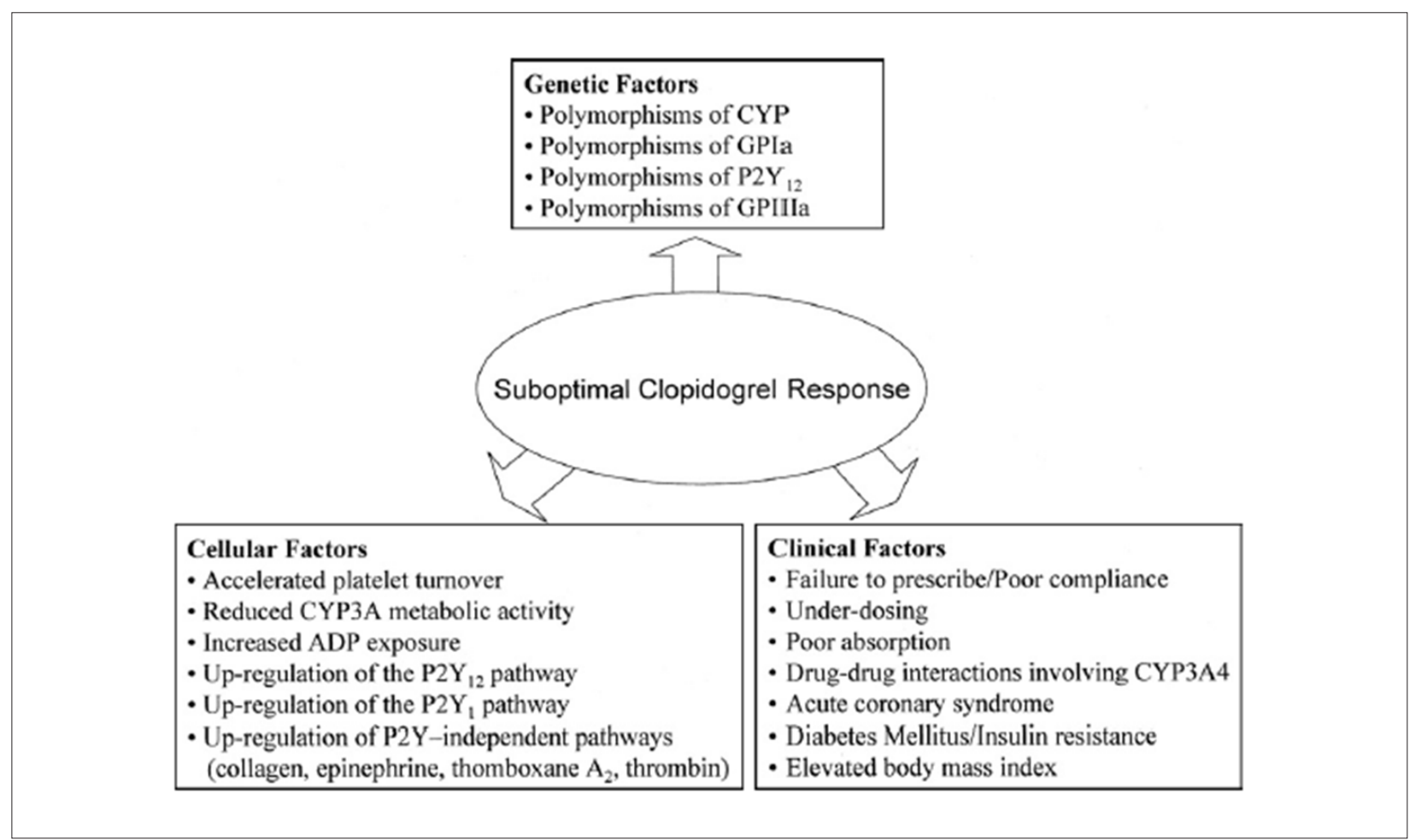

Figure 7 - Proposed mechanisms leading to variability in individual responsiveness to clopidogreß1. ADP-Adenosine diphosphate; CYP-cytochrome P450; GP-glycoprotein.

for by a large reduction in restenosis and the need for repeat revascularization compared with BMS. Reassuringly also, many large real-world registries have reported low rates of late stent thrombosis even in more complex patient groups.
There have been several beneficial outcomes from the DES backlash of 2006-2007: the development of a uniform definition of stent thrombosis events in research studies, better follow-up in research studies and better collaboration 


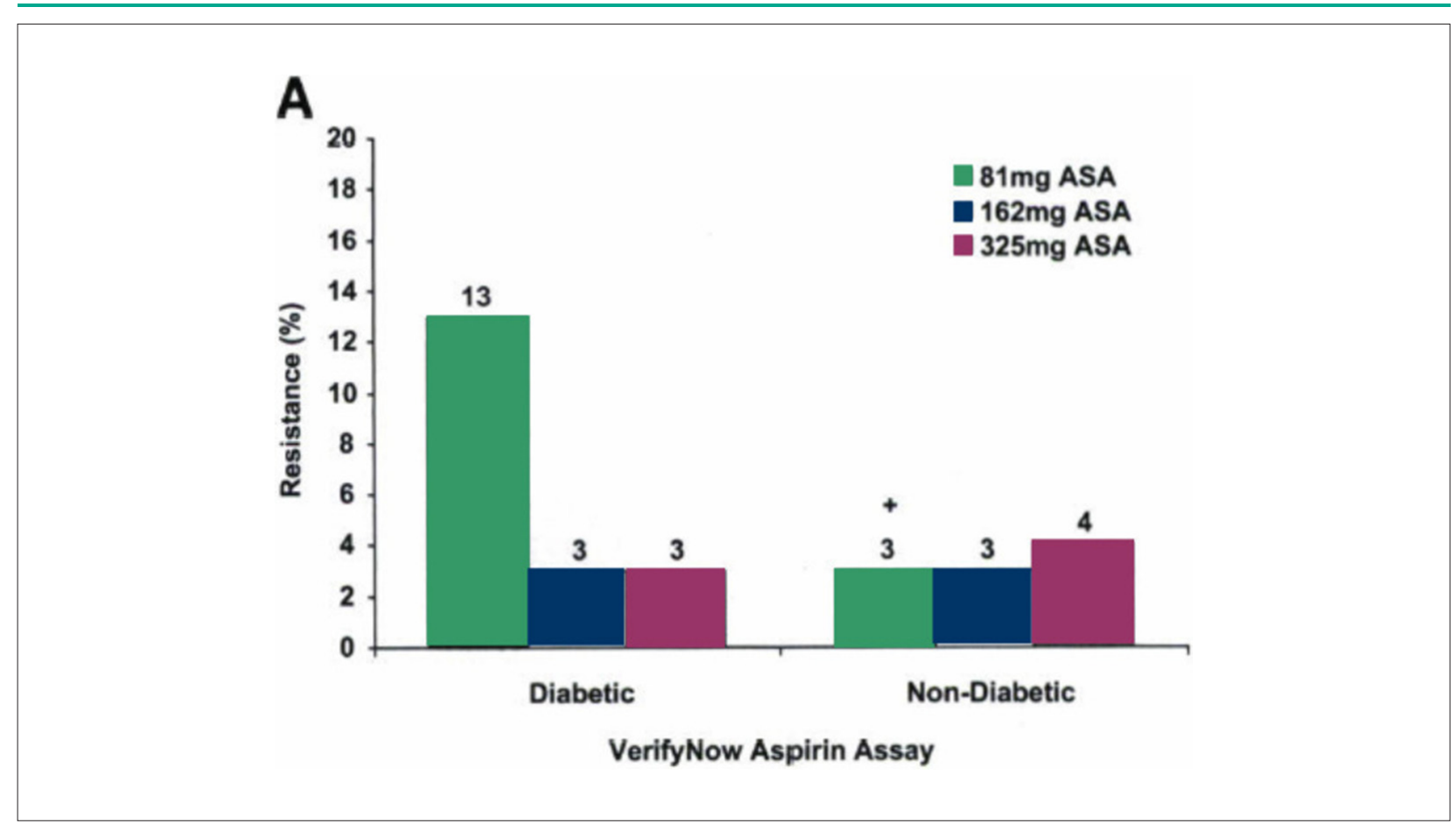

Figure 8 - Graph demonstrating the prevalence of Aspirin resistance (\%) measured by VerifyNow in diabetic and non-diabetic patients at 3 doses of aspirin ${ }^{33}$.

and transparency between research institutions and industry. DES have undoubtedly benefited many patients already, and the next generation seems set to extend this to many more.

\section{References}

1. Baim D. What does the future hold? In: Symposium "The Great debate on coronary dru-eluting stents. Toulose, 200722 May.[Accessed 2008 Feb 10]. Available from :http://europcronline.congrhealth.com/Fo/lecture/zoom

2. Sousa AG, Mattos LA, Campos Neto CM, Carvalho HG, Stella FP, Nunes G. Percutaneous myocardial revascularization procedures in Brazil in 19961997 compared to the 1992-1993 period: a report of the National Registry-National Center for Cardiovascular Interventions (CENIC)]. Arq Bras Cardiol. 1998; 70: 423-30.

3. Morice MC, Serruys PW, Sousa JE, Fajadet J, Ban HE, Perin M, et al. A randomized comparison of a sirolimus-eluting stent with a standard stent for coronary revascularization. N Engl J Med. 2002; 346: 1773-80.

4. Moses JW, Leon MB, Popma JJ, Fitzgerald PJ, Holmes DR, O'Shaughnessy C, et al. Sirolimus-eluting stents versus standard stents in patients with stenosis in a native coronary artery. N Engl J Med. 2003; 349: 1315-23.

5. Stone GW, Ellis SG, Cox DA, Hermiller J, O'Shaughnessy C, Mann JT, et al One-year clinical results with the slow-release, polymer-based, paclitaxeleluting TAXUS stent: the TAXUS-IV trial. Circulation. 2004; 109: 1942-7.

6. McFadden EP, Stabile E, Regar E, Cheneau E, Ong AT, Kinnaird T, et al. Late thrombosis in drug-eluting coronary stents after discontinuation of antiplatelet therapy. Lancet. 2004; 364: 1519-21.
7. Joner M, Finn AV, Farb A, Mont EK, Kolodgie FD, Ladich E, et al. Pathology of drug-eluting stents in humans: delayed healing and late thrombotic risk. J Am Coll Cardiol. 2006; 48: 193-202.

8. Pfisterer M, Brunner-La Rocca HP, Buser PT, Rickenbacher P, Hunziker P, Mueller C, et al. Late clinical events after clopidogrel discontinuation may limit the benefit of drug-eluting stents: an observational study of drug-eluting versus bare-metal stents. J Am Coll Cardiol. 2006; 48: 2584-91.

9. Camenzind E, Steg PG, Wijns W. Safety of drug-eluting stent: a meta-analysis of 1st generation DES programs. In: World Congress of Cardiology 2006; Sept 2-6, 2006; Barcelona.[Accessed 2007 Jan 10]. Available from: http:www. escardio.org/knowledge/congresses.

10. Nordmann AJ, Briel M, Bucher HC. Mortality in randomized controlled trials comparing drug-eluting vs. bare metal stents in coronary artery disease: a meta-analysis. Eur Heart J. 2006; 27: 2784-814

11. Millenium Research Group. US Market Research Source Book. Cardiovascular: Coronary stents. by clinical indications; 2007.[Accessed 2007 Dec 08]. Available from: http://www.mrg.net/reportView.php?repID $=533 \&$ logged $=\&$ keywords $=$ drug-eluting $\% 20$ stent $\% 20$.

12. Millenium Research Group. European Market for Interventional Cardiology - France, Germany, Italy, UK. http://www.mrg.net/reportView.php?repID= $505 \&$ logged $=\&$ keywords = drug-eluting $\% 20$ stent $\% 20$ penetration 
13. U.S.Food and Drug Administration. Summary from the Circulatory System Devices Panel Meeting. December 7\&8,2006. [Accessed 2007 Nov 13] Available from: http://www.fda.gov/cdrh/panel/summary/circ/12076/html.

14. Mauri L, Hsieh WH, Massaro JM, Ho KK, D'Agostino R, Cutlip DE. Stent thrombosis in randomized clinical trials of drug-eluting stents. N Engl J Med. 2007; 356: 1020-9.

15. Stone GW, Moses JW, Ellis SG, Schofer J, Dawkins KD, Morice MC, et al. Safety and efficacy of sirolimus- and paclitaxel-eluting coronary stents. N Engl J Med. 2007; 356: 998-1008.

16. Spaulding C, Daemen J, Boersma E, Cutlip DE, Serruys PW. A pooled analysis of data comparing sirolimus-eluting stents with bare-metal stents. N Engl J Med. 2007; 356: 989-97.

17. Lagerqvist B, James SK, Stenestrand U, Lindback J, Nilsson T, Wallentin L. Long-term outcomes with drug-eluting stents versus bare-metal stents in Sweden. N Engl J Med. 2007; 356: 1009-19.

18. James SK, Carlsson J, Lindback J, Nilsson T, Stenestrand U, Wallentin L, et al. SCAAR - Long term mortality after drug eluting stents in Sweden, an additional year of follow-up.clinical trial update 1. European Society of Cardiology Annual Scientific Conference. http://www.escardio.org/knowledge/ congresses/CongressReports/2007/hl-ctu/1021-james-ctu1.htm

19. Applegate RJ, Sacrinty MT, Kutcher MA, Baki TT, Gandhi SK, Santos RM, et al. Comparison of drug-eluting versus bare metal stents on later frequency of acute myocardial infarction and death. Am J Cardiol. 2007; 99: 333-8.

20. Abbott JD, Voss MR, Nakamura M, Cohen HA, Selzer F, Kip KE, et al. Unrestricted use of drug-eluting stents compared with bare-metal stents in routine clinical practice: findings from the National Heart, Lung, and Blood Institute Dynamic Registry. J Am Coll Cardiol. 2007; 50: 2029-36.

21. Marzocchi A, Saia F, Piovaccari G, Manari A, Aurier E, Benassi A, et al. Long-term safety and efficacy of drug-eluting stents: two-year results of the REAL (REgistro AngiopLastiche dell'Emilia Romagna) multicenter registry. Circulation. 2007; 115: 3181-8.

22. Tu JV, Bowen J, Chiu M, Ko DT, Austin PC, HeY, et al. Effectiveness and safety of drug-eluting stents in Ontario. N Engl J Med. 2007; 357: 1393-402.

23. Stettler C, Wandel S, Allemann S, Kastrati A, Morice MC, Schomig A, et al. Outcomes associated with drug-eluting and bare-metal stents: a collaborative network meta-analysis. Lancet. 2007; 370: 937-48.

24. Kirtane AJ, Ellis SG, Dawkins KD, Colombo A, Grube E, Popma JJ, et al. Paclitaxel-eluting coronary stents in patients with diabetes mellitus: pooled analysis from 5 randomized trials. J Am Coll Cardiol. 2008; 51: 708-15.

25. Stone GW, Ellis SG, Colombo A, Dawkins KD, Grube E, Cutlip DE, et al.
Offsetting impact of thrombosis and restenosis on the occurrence of death and myocardial infarction after paclitaxel-eluting and bare metal stent implantation. Circulation. 2007; 115: 2842-7.

26. Kereiakes DJ, Choo JK, Young JJ, Broderick TM. Thrombosis and drug-eluting stents: a critical appraisal. Rev Cardiovasc Med. 2004; 5: 9-15.

27. Ramos AR, Morice MC, Lefevre T. Late or very late stent thrombosis can also occur with bare metal stents. Catheter Cardiovasc Interv. 2007; 70: 229-32.

28. Fujii K, Carlier SG, Mintz GS, Yang YM, Moussa I, Weisz G, et al. Stent underexpansion and residual reference segment stenosis are related to stent thrombosis after sirolimus-eluting stent implantation: an intravascular ultrasound study. J Am Coll Cardiol. 2005; 45: 995-8.

29. Machecourt J, Danchin N, Lablanche JM, Fauvel JM, Bonnet JL, Marliere S, et al. Risk factors for stent thrombosis after implantation of sirolimus-eluting stents in diabetic and nondiabetic patients: the EVASTENT Matched-Cohort Registry. J Am Coll Cardiol. 2007; 50: 501-8.

30. Buonamici P, Marcucci R, Migliorini A, Gensini GF, Santini A, Paniccia R, et al Impact of platelet reactivity after clopidogrel administration on drug-eluting stent thrombosis. J Am Coll Cardiol. 2007; 49: 2312-7.

31. Angiolillo DJ, Fernandez-Ortiz A, Bernardo E, Alfonso F, Macaya C, Bass TA, et al. Variability in individual responsiveness to clopidogrel: clinical implications, management, and future perspectives. J Am Coll Cardiol. 2007; 49: 1505-16.

32. Angiolillo DJ, Fernandez-Ortiz A, Bernardo E, Ramirez C, Sabate M, JimenezQuevedo P, et al. Clopidogrel withdrawal is associated with proinflammatory and prothrombotic effects in patients with diabetes and coronary artery disease. Diabetes. 2006; 55: 780-4.

33. Dichiara J, Bliden KP, Tantry US, Hamed MS, Antonino MJ, Suarez TA, et al. The effect of aspirin dosing on platelet function in diabetic and nondiabetic patients: an analysis from the aspirin-induced platelet effect (ASPECT) study. Diabetes. 2007; 56: 3014-9.

34. Angiolillo DJ, Fernandez-Ortiz A, Bernardo E, Ramirez C, Sabate M, JimenezQuevedo P, et al. Influence of aspirin resistance on platelet function profiles in patients on long-term aspirin and clopidogrel after percutaneous coronary intervention. Am J Cardiol. 2006; 97: 38-43.

35. Aoki J, Serruys PW, van Beusekom H, Ong AT, McFadden EP, Sianos G, et al. Endothelial progenitor cell capture by stents coated with antibody against CD34: the HEALING-FIM (Healthy Endothelial Accelerated Lining Inhibits Neointimal Growth-First In Man) Registry. J Am Coll Cardiol. 2005; 45: 1574-9.

36. Ormiston JA, Serruys PW, Regar E, Dudek D, Thuesen L, Webster MW, et al. A bioabsorbable everolimus-eluting coronary stent system for patients with single de-novo coronary artery lesions (ABSORB): a prospective open-label trial. Lancet. 2008; 371: 899-907. 